\title{
High expression of ABCG2 is associated with chemotherapy resistance of osteosarcoma
}

\author{
Hao Shu', Bin Yuan', Yao Huang ${ }^{1}$, Lei Wang ${ }^{1}$, Bing He ${ }^{1}$, Qi Sun² and Luning Sun ${ }^{1 *}$
}

\begin{abstract}
Objectives: Previous studies showed overexpression of ABCG2 in a variety of tumor tissues, which could potentially indicate the probability of chemotherapy resistance. This study aimed to reveal the role of ABCG2 in the development of chemotherapy resistance and the prognosis of osteosarcoma (OS).

Methods: Sixty-eight OS patients were included in this study. Tumor tissues were collected for each patient during surgery. DOX-resistant OS cell lines were induced by consecutive exposure of gradually increasing concentration of DOX to the parental cell lines. Lentivirus was used for the knockdown of ABCG2 in OS cells. Cells were treated with the gradient concentration of DOX, and the viability was assessed by CCK8 assay. Total RNA was isolated from the tumor tissues or tumor cells, and the expression of ABCG2 was analyzed by qPCR. The relationship between ABCG2 expression and clinicopathological characteristics of the patients was analyzed using Student's $t$ test or the Chi-square test. The overall survival time was calculated by the Kaplan-Meier method and analyzed by the log-rank test. $p<0.05$ was considered statistically significant.
\end{abstract}

Results: DOX-resistant OS cells were successfully established through continuous exposure to DOX. Forty-eight hours after DOX exposure, the IC 50 value of DOX-resistant HOS cells and DOX-resistant U2OS was $3.5 \mu \mathrm{M}$ and $3.25 \mu \mathrm{M}$, respectively. By contrast, those of the untreated HOS and U2OS cells were $1.15 \mu \mathrm{M}$ and $0.93 \mu \mathrm{M}$, respectively $(p<0.01)$. The mRNA expression level of ABCG2 was significantly increased in DOX-resistant cell lines. The CCK-8 assay showed that the DOX-resistant HOS cells and DOX-resistant U2OS cells transfected with ShABCG2 were more sensitive to the DOX treatment than those transfected with ShCtrl. Analysis of gene expression in OS tissues showed remarkably higher expression of ABCG2 as compared with adjacent normal tissues $(p<0.01)$. Patients with high expression level of ABCG2 had obviously decreased overall survival time than the patients with normal expression $(p<0.01)$.

Conclusions: ABCG2 expression level was significantly associated with the resistance to chemotherapy and the overall survival of OS patients. ABCG2 may be a promising therapeutic target for OS patients.

Keywords: Osteosarcoma, ABCG2, Chemoresistance, Prognosis

\footnotetext{
* Correspondence: sunluningsportsmedicine@163.com

'Department of Orthopedics, Sports Medicine Center, Affiliated Hospital of

Nanjing University of Chinese Medicine, Hanzhong Road 115, Nanjing

210029, China

Full list of author information is available at the end of the article
}

(C) The Author(s). 2021 Open Access This article is licensed under a Creative Commons Attribution 4.0 International License, which permits use, sharing, adaptation, distribution and reproduction in any medium or format, as long as you give appropriate credit to the original author(s) and the source, provide a link to the Creative Commons licence, and indicate if changes were made. The images or other third party material in this article are included in the article's Creative Commons licence, unless indicated otherwise in a credit line to the material. If material is not included in the article's Creative Commons licence and your intended use is not permitted by statutory regulation or exceeds the permitted use, you will need to obtain permission directly from the copyright holder. To view a copy of this licence, visit http://creativecommons.org/licenses/by/4.0/ The Creative Commons Public Domain Dedication waiver (http://creativecommons.org/publicdomain/zero/1.0/) applies to the data made available in this article, unless otherwise stated in a credit line to the data. 


\section{Introduction}

Osteosarcoma (OS) is the most common malignant bone tumor characterized by a high incidence of distant metastasis $[1,2]$. Before the advent of neo-adjuvant chemotherapy, OS patients undergoing amputation or reconstruction surgery had low 5-year survival rates averaging approximately 15$20 \%[3,4]$. Benefited from the multi-agent neo-adjuvant chemotherapy, the 5-year survival rate now rises up to $70 \%$ for patients with non-metastatic OS [5]. However, it is noteworthy that patients with poor survival rate showed worse responsiveness to chemotherapy. In the past years, different approaches have been applied to investigate the mechanisms involved in chemoresistance of OS [6, 7]. It was speculated that intrinsic gene expression differences may account for the low responsiveness to chemotherapy, while the precise underlying mechanisms remain poorly understood. Herein, identification of genes associated with chemoresistance is of great importance to personalize an effective regimen of chemotherapy.

First cloned from doxorubicin-resistant breast cancer cells, the human ABCG2 gene encodes ATP binding cassette $(A B C)$ transporters that drive the transport of various substrates across cell membranes [8, 9]. Previous studies showed that ABCG2 plays an important role in the proliferation and differentiation of stem cells [10, 11]. Moreover, overexpression of ABCG2 has been observed in a variety of tumor tissues, which could potentially indicate the probability of chemotherapy resistance $[12,13]$. Noguchi et al. [13] reported that ABCG2 was related to drug resistance in the breast cancer. Damiani et al. observed that overexpression of ABCG2 could significantly affect the duration of complete remission, which therefore might be regarded as a prognostic factor in patients with acute myeloid leukemia [12].

To our knowledge, studies concerning the role of ABCG2 in OS chemoresistance are still limited. Yet, few studies have investigated the regulatory mechanism underlying ABCG2 expression in OS tissues. In this study, we aimed to investigate the role of ABCG2 in the development of doxorubicin (DOX) resistance and the prognosis of OS. Moreover, we investigated the association of genetic polymorphism with tissue expression of ABCG2 and the chemotherapy resistance of OS patients.

\section{Methods}

\section{Subjects}

Under the approval by the local institutional Ethics Committee, 68 OS patients undergoing treatment in our clinic centers between 2008 March and 2013 January were included in this study. All the patients were histologically diagnosed as OS. Baseline characteristics of the patients were collected from the medical record, including age, gender, tumor size, histologic differentiation, and Enneking stages. Before the surgery, all the patients had received two cycles of neoadjuvant chemotherapy composed of DOX, methotrexate, and cisplatin. Tumor tissues were collected from each patient during surgery. Good response to the chemotherapy was histologically defined as more than $90 \%$ necrosis rate in the tumor tissues. All patients signed written informed consent concerning the collection of blood and tissue samples.

\section{Cell culture and establishment of DOX resistance}

The human OS cell lines U2OS and HOS were purchased from the American Type Culture Collection (ATCC, Rockville, MD, USA). All cell lines were cultured in Dulbecco's modified Eagle's medium (4.5 g/l glucose)/ Ham F12 (1:1) (Invitrogen, Carlsbad, CA, USA) supplemented with $10 \%$ fetal calf serum (FCS). All cells were cultured at $37^{\circ} \mathrm{C}$ in a humidified atmosphere of $5 \% \mathrm{CO}_{2}$. DOX was purchased from Sigma (Buchs, Switzerland). DOX-resistant cell lines were induced by consecutive exposure of gradually increasing concentration of DOX to the parental cell lines for 6 months as previously reported. As a starting concentration, $0.015 \mu \mathrm{M}$ DOX was applied, and the concentration was gradually increased up to $0.12 \mu \mathrm{M}$ in a period of 3 months. One month after exposure to $0.12 \mu \mathrm{M}$ doxorubicin, the resistance stability was defined as not significantly altered IC50 of U2OS and HOS cells when incubated in DOX for a week.

\section{Knockdown of ABCG2 in OS cells}

The lentivirus shRNA specifically targeting ABCG2 (shABCG2) and the negative control scramble shRNA (shCtrl) were designed and constructed by Shanghai Genechem Company Ltd., China. Lentivirus particles were generated by co-transfecting recombined and packing vectors into 293T cells via Lipofectamine 2000 (Invitrogen, Carlsbad, CA, USA). U2OS and HOS cells were then cultured in 6-well plates and transfected with shABCG2 or shCtrl. Both cells lines were cultured for 5 days. The knockdown efficiency of the target gene was further evaluated for both cell lines with qPCR analysis and western blot (WB).

\section{Cell proliferation assay}

Cell proliferation was analyzed by the colorimetric water-soluble tetrazolium salt assay using a Cell Counting Kit-8 (CCK8) according to the manufacturer's instructions (Dojindo, Tokyo, Japan). Cells were treated with the gradient concentration of $\operatorname{DOX}(0,0.5,1.0,2.0$, $4.0,8.0 \mu \mathrm{M})$ for $24 \mathrm{~h}$, and then cultured for another $48 \mathrm{~h}$. CCK-8 reagent $(10 \mu \mathrm{L})$ was added to each well, followed by incubation for $1 \mathrm{~h}$ in a humidified atmosphere $\left(37^{\circ} \mathrm{C}\right.$, $5 \% \mathrm{CO}_{2}$ ). The number of viable cells was evaluated by the absorbance at $450 \mathrm{~nm}$ using a microplate reader (Tecan Spectra Fluor Plus, Crailsheim, Germany), which was then repeated with 3 replicates. 


\section{qPCR}

Total RNA was isolated from the tumor tissues or tumor cells using TRIzol reagent (Invitrogen, Carlsbad, CA, USA) according to the manufacturer's protocol. Reverse transcription into cDNA was performed with a SuperScript III Reverse Transcriptase kit (Invitrogen, Carlsbad, CA, USA). The quantitative gene expression level was measured using SYBR Master Mixture (TAKARA, Tokyo, Japan) on the LightCycler 480 (Roche Applied Science, Mannheim, Germany). Glyceraldehyde 3-phosphate dehydrogenase (GAPDH) was used as the internal control. The sequences of the primers were as follows: ABCG2, 5' - GCCACAGAGATCATAGAG CCT -3', 5' - TCACCCCCGGAAAGTTGATG -3'; GAPD H, 5'- GAGTCAACGGATTTGGTCGT -3', reverse 5' -TTGATTTTGGAGGGATCTCG- 3'. Quantitative analysis normalized to GAPDH was performed using the $2^{-\Delta \Delta \mathrm{Ct}}$ method. All the experiments were performed with 3 replicates.

\section{Western blot analysis}

Cell lysis buffer was used for the preparation of total cell proteins. Cell lysates were separated equally on a $10-12 \%$ SDS polyacrylamide gel, which was then electrotransferred to polyvinylidene fluoride membranes (Immobile P; Millipore) and blocked with 5\% nonfat dry milk in TBST for $1 \mathrm{~h}$. Membranes were immunoblotted with the primary antibody (Abcam) overnight at $4{ }^{\circ} \mathrm{C}$, and then incubated with second antibody (Cell Signaling Technology) for $2 \mathrm{~h}$ at room temperature. The signals were detected by enhanced chemiluminescence (Thermo) with GAPDH used as a loading control.

\section{Immunohistochemical staining}

Paraffin-embedded tissue samples were cut into 4- $\mu \mathrm{m} \mathrm{sec-}$ tions and deparaffinized for immunohistochemical staining (IHC). Slides were then incubated with primary anti ABCG2 antibody (1:400, Abcam) overnight at $4{ }^{\circ} \mathrm{C}$, followed by incubation with secondary antibody for 30 min at $20^{\circ} \mathrm{C}$. All slides were stained by diaminobenzidine and then counterstained by hematoxylin. The IHC-stained tissue sections were scored by two pathologists. The signal intensity was scored as follows: score 0 , no signal; score 1 , weak; score 2, moderate; and score 3, marked. The staining distribution was scored as follows: score 0 , no positive staining cells; score 1, 1-30\% positive staining cells; score $2,31-60 \%$ positive staining cells; score $3,61-100 \%$ positive staining cells. The final score was calculated by multiplying the score of staining distribution with the signal intensity score. Remarkably higher staining of ABCG2 was defined as the score more than 2 .

\section{Genotyping of functional variant}

DNA was extracted using the DNA extraction kit (QIAGEN Inc., Tokyo, Japan) according to the protocol of the manufacturers. SNP rs2231142 (c.421C > A) was genotyped using TaqMan SNP Genotyping Assay. The flanking amplified sequence for the genotyping analysis was as follows: CACCATGGATTAGGAGATCATCAG AGGTC[A/C]CGGACCCCTCTCTGTTACTGAGA-

CATTTG. The genotyping assay was performed with ABI 7900HT Sequence Detection System (Applied Biosystems, Foster City, CA).

\section{Statistical analysis}

The results were presented as mean \pm standard deviation and analyzed with the SPSS software (version 19.0; SPSS Inc, Chicago, IL, USA). The data was shown as means \pm SD for continuous variables. The relationship between ABCG2 expression and clinicopathological characteristics of the patients was analyzed using Student's $t$ test or the Chi-square test. The gene expression and the overall survival were compared among different genotypes of rs2231142 with one-way ANOVA test. The overall survival time was calculated by the Kaplan-Meier method and analyzed by the log-rank test. $P<0.05$ was considered statistically significant.

\section{Results}

\section{Demographic data}

The demographic and clinical characteristics of the study subjects are shown in Table 1 . The mean age of patients with OS was $35.2 \pm 16.1$ years. Thirty patients

Table 1 Baseline characteristics of the patients

\begin{tabular}{ll}
\hline Features & Patients $(\boldsymbol{n}=\mathbf{6 8})$ \\
\hline Gender & 30 \\
Male & 38 \\
Female & \\
Age (years) & 34 \\
$>20$ & 34 \\
$\leq 20$ & \\
Enneking stages & 13 \\
I & 17 \\
IIA & 27 \\
IIB & 11 \\
III & \\
Histologic type & 35 \\
Osteoblastic & 17 \\
Chondroblastic & 2 \\
Fibroblastic & 14 \\
Mixed & \\
Tumor size (cm) & 41 \\
$>5$ & 27 \\
$\leq 5$ &
\end{tabular}


were male, and 38 patients were female. Fifty-seven $(83.8 \%)$ patients were at tumor stages I-II. Fifty-four (78.4\%) patients received limb salvage treatment. After surgery, 27 (39.7\%) patients were found to have good response to the chemotherapy. After a mean period of 39.5 months (range, 8-60 months) follow-up, 32 (47.1\%) patients had died from all causes.

\section{ABCG2 was overexpressed in DOX-resistant OS cells}

Figure 1 showed that DOX-resistant OS cells were successfully established through continuous exposure to DOX. Forty-eight hours after DOX exposure, the IC 50 value of DOX-resistant HOS cells and DOX-resistant $\mathrm{U} 2 \mathrm{OS}$ were $3.5 \mu \mathrm{M}$ and $3.25 \mu \mathrm{M}$, respectively. By contrast, those of the untreated HOS and U2OS cells were $1.15 \mu \mathrm{M}$ and $0.93 \mu \mathrm{M}$, respectively $(p<0.01)$. The results of qPCR analysis showed that mRNA expression level of ABCG2 was significantly increased in DOX-resistant cell lines (Fig. 1).

\section{Knockdown of ABCG2 enhanced response to DOX in OS} cells

As shown in Fig. 2, the mRNA and protein expression level of ABCG2 were remarkably decreased in both ABCG2-inhibited HOS and U2OS cells as compared with the control cells. After being incubated with DOX for $48 \mathrm{~h}$, the viability of cells transfected with shABCG2 was remarkably lower than that of cells transfected with shCtrl. The IC 50 value of ShABCG2-transfected HOS cells and ShABCG2-transfected U2OS was $3.25 \mu \mathrm{M}$ and $3.05 \mu \mathrm{M}$, respectively. By contrast, the IC 50 value of HOS and U2OS cells in the control group was $1.05 \mu \mathrm{M}$ and $0.97 \mu \mathrm{M}$, respectively $(p<0.01)$.

\section{High expression level of ABCG2 was associated with a} poor prognosis of OS

The ABCG2 expression was analyzed in the tumor tissues and adjacent normal tissues of 68 patients. As shown in Fig. 3, ABCG2 was obviously highly expressed in the tumor tissues than in the normal tissues $(p<$
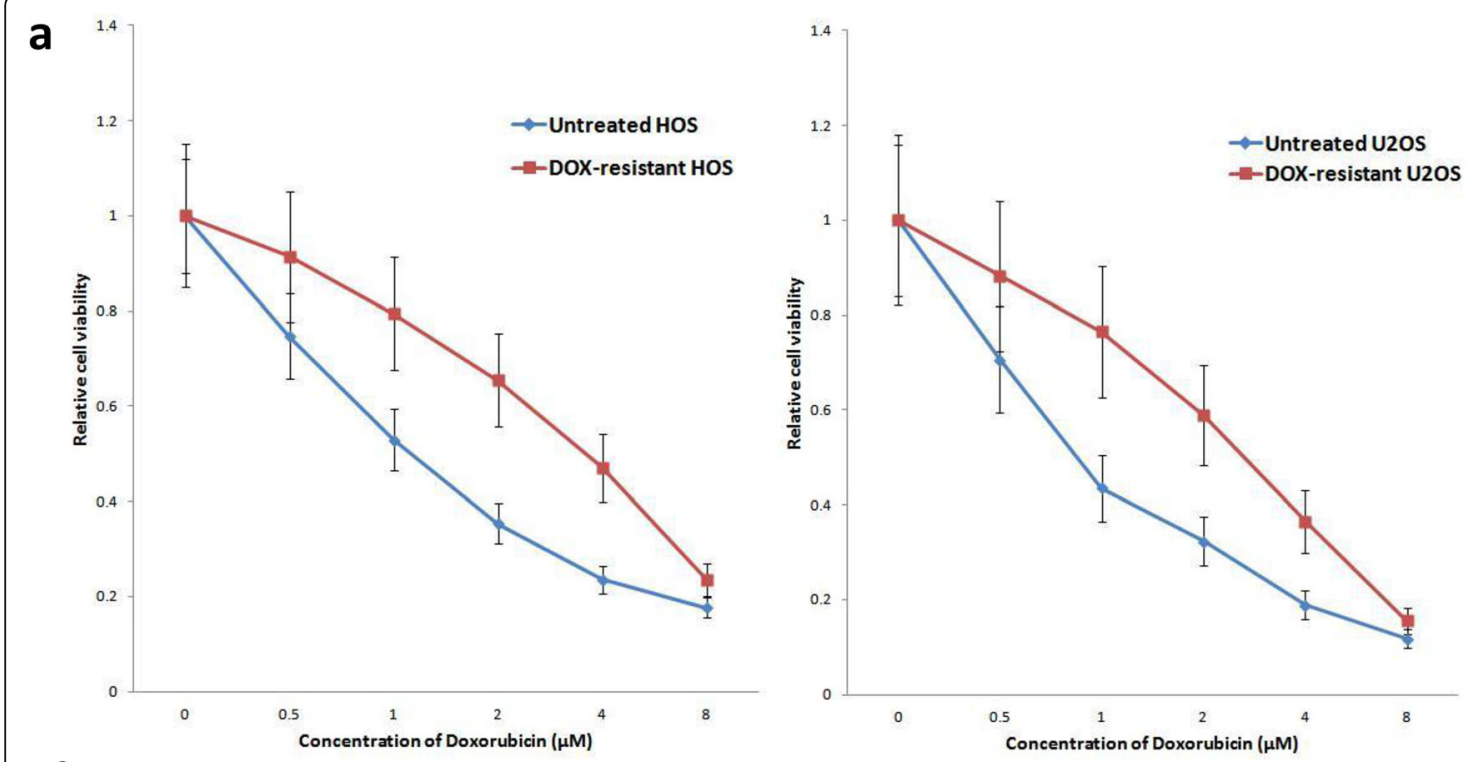

b
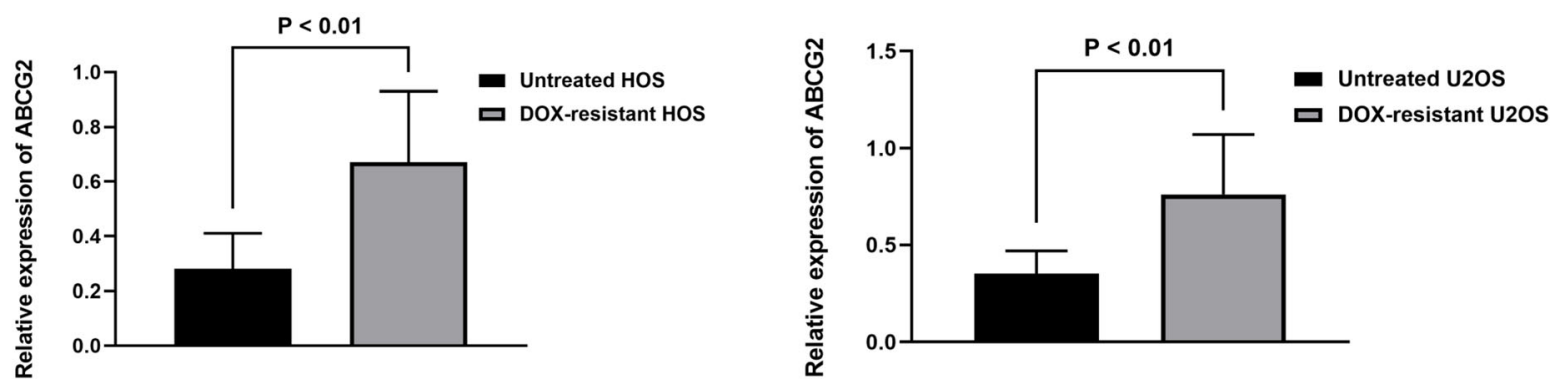

Fig. 1 Upregulated expression of ABCG2 in DOX-resistant OS cells. a Successful establishment of DOX-resistant OS cell lines was verified by CCK8 assay. Cell viability of DOX-treated HOS cells and U2OS cells was remarkably higher than those not treated by DOX. b Through qPCR, we confirmed that mRNA expression level of ABCG2 was significantly increased in DOX-resistant cell lines as compared with normal cell lines 


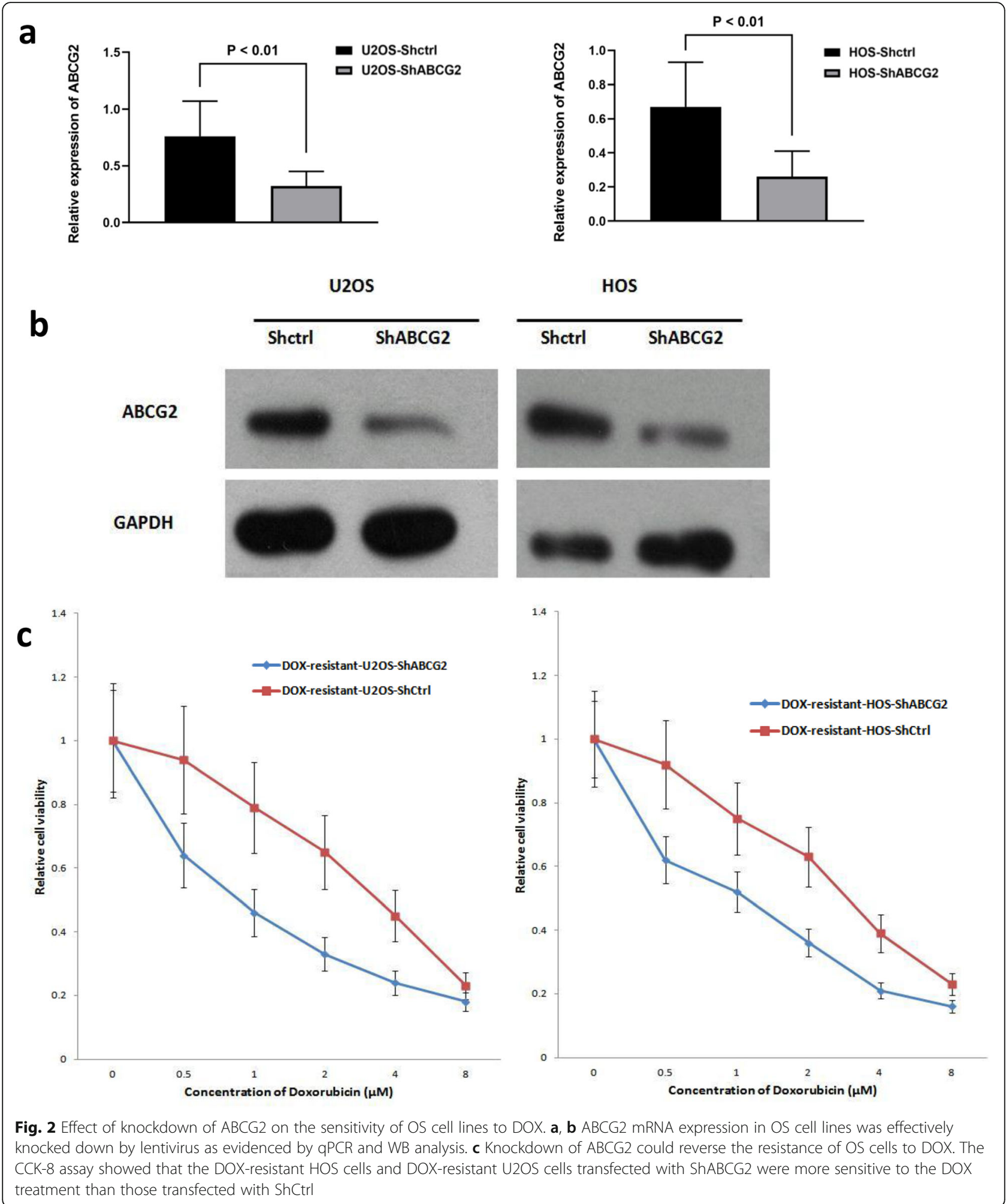

0.001). According to the results of IHC, 43 patients were included in the high expression group and the other 25 patients were included in the normal expression group (Supplementary Figure 1). As shown in Table 2, we found that ABCG2 expression was significantly associated with tumor size $(6.1 \mathrm{~cm} \pm 2.7 \mathrm{~cm}$ vs. $3.9 \mathrm{~cm} \pm 1.5$ $\mathrm{cm}, p=0.01)$ and the response to chemotherapy $(62.4 \%$ $\pm 25.1 \%$ vs. $75.3 \% \pm 18.7 \%, p=0.02$ ). As shown in Fig. 3 , 


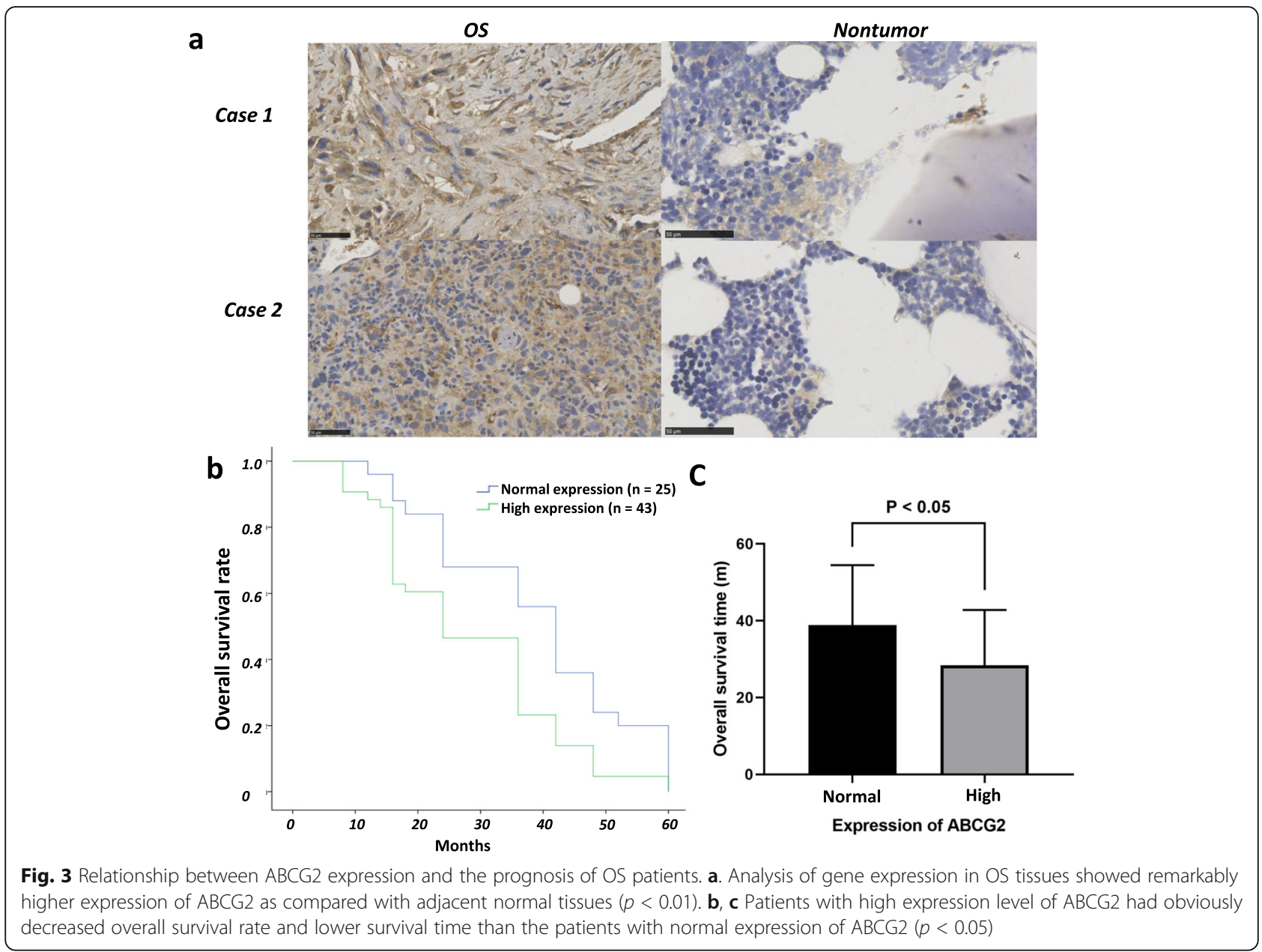

the overall survival time of patients with normal ABCG2 expression was significantly longer than those of the high ABCG2 expression (38.9 \pm 15.6 months vs. $28.4 \pm$ 14.4 months, $p<0.01$ ). No significant association was found between ABCG2 expression and other clinical features (Table 2).

SNP rs2231142 might play a functional role in the ABCG2asociated prognosis of OS

Genotyping of rs2231142 was successfully completed for all the patients. Of the 68 patients, there were 31 patients with genotype $\mathrm{CC}, 24$ with genotype $\mathrm{CA}$, and 13 with genotype AA. The mRNA expression of ABCG2 in tumor tissues was analyzed for each patient. As shown in Fig. 4, patients carrying genotype AA had remarkably lower expression of ABCG2 than those with genotype CC $(0.53 \pm$ 0.21 vs. $0.82 \pm 0.35, p<0.01)$. Moreover, patients carrying the genotype AA were associated with longer overall survival time as compared with those with genotype CC (44.1 \pm 14.3 months vs. $25.6 \pm 12.1$ months, $p<0.01$ ) (Fig. 4).

\section{Discussion}

Chemotherapy regimen composed of DOX, methotrexate, and cisplatin is most commonly applied for patients with OS $[5,14]$. However, resistance to chemotherapeutic drugs remains the primary obstacle to achieve favorable outcome of human cancer. Various factors leading to chemoresistance have been reported in previous studies, such as alterations in the drug target, abnormal induction of cell death pathways, and overexpression of ABC membrane transporter family members [15-17]. Nevertheless, there is still a lack of methods to predict chemoresistance in OS effectively. Obviously, identifying new contributing factors of chemoresistance in OS is of great importance to improve the therapeutic efficacy and predict the drug response.

High ABCG2 expression has been identified in a variety of solid tumors and has been correlated with poorer clinical outcomes [8-10]. In a recent study, Tsai et al. [18] reported that ABCG2 overexpression could decrease the therapeutic effect of DOX in OS cells. For the first time, we confirmed the role of ABCG2 in the development of 
Table 2 Relation between ABCG2 expression and clinical features of the patients

\begin{tabular}{|c|c|c|c|}
\hline & \multicolumn{2}{|l|}{ ABCG2 expression } & \multirow[t]{2}{*}{$p$} \\
\hline & Normal expression $(n=25)$ & High expression $(n=43)$ & \\
\hline \multicolumn{4}{|l|}{ Age (years) } \\
\hline$>20$ & 13 & 21 & \multirow[t]{2}{*}{0.65} \\
\hline$\leq 20$ & 12 & 22 & \\
\hline Mean \pm S.D. & $34.5 \pm 15.7$ & $35.6 \pm 14.9$ & 0.77 \\
\hline \multicolumn{4}{|l|}{ Gender } \\
\hline Male & 11 & 19 & \multirow[t]{2}{*}{0.98} \\
\hline Female & 14 & 24 & \\
\hline \multicolumn{4}{|l|}{ Enneking stages } \\
\hline । & 4 & 9 & \multirow[t]{4}{*}{0.35} \\
\hline$\| \mathrm{A}$ & 7 & 10 & \\
\hline$\| B$ & 12 & 15 & \\
\hline III & 2 & 9 & \\
\hline Tumor size (cm) & $3.9 \pm 1.5$ & $6.1 \pm 2.7$ & $<0.01$ \\
\hline Overall survival (month) & $38.9 \pm 15.6$ & $28.4 \pm 14.4$ & $<0.01$ \\
\hline
\end{tabular}

chemoresistance using the established DOX-resistant OS cell lines. Comparably, through Genechip analysis, Walters et al. [19] identified increased expression of ABCG2 in the OS cell lines treated by doxorubicin. Compared with their parental DOX-sensitive cells, DOX-resistant cells were observed to have remarkably elevated expression level of ABCG2. Furthermore, knockdown of ABCG2 level in DOX-resistant cell lines by lentivirus could effectively recover the therapeutic efficacy of DOX treatment.
Of note, we found that ABCG2 expression level was significantly increased in patients with decreased overall survival and poor response to chemotherapy. It was in accordance with previous study reporting that elevated levels of ABCG2 have a vital role in OS prognosis [20]. On the basis of these data, we proposed that ABCG2 may become a promising therapeutic target for OS patients. These characteristics of ABCG2 enable it a promising molecular target to guide the chemotherapy treatment of OS.
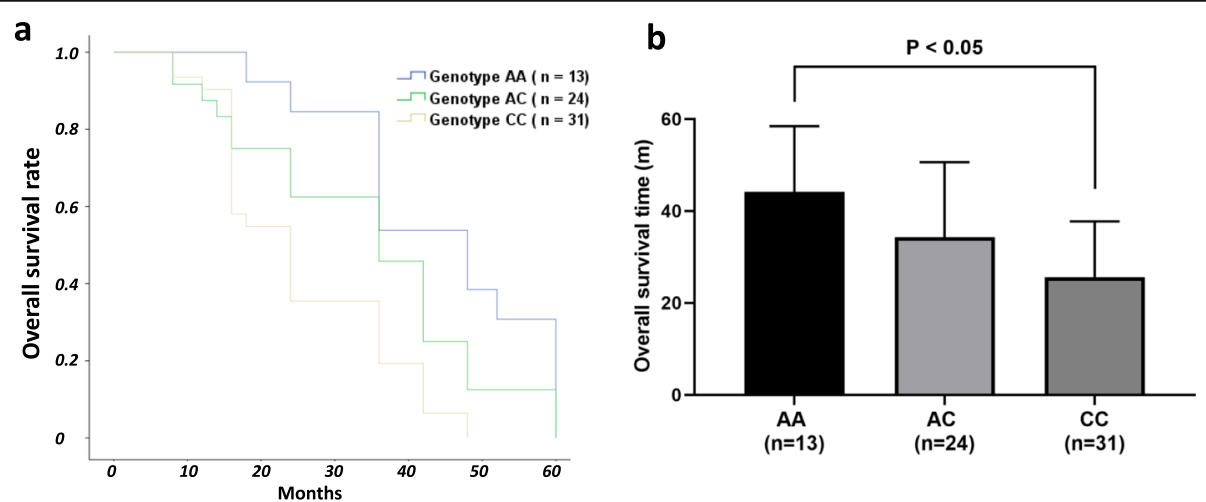

C

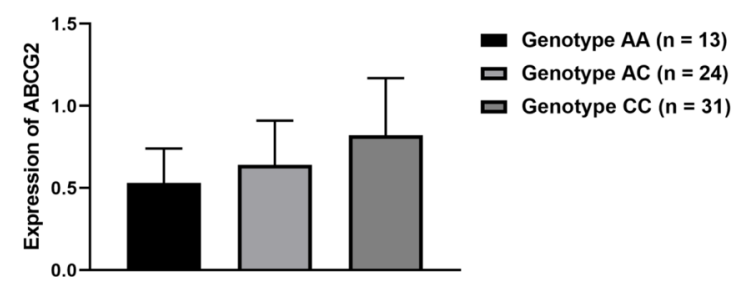

Fig. 4 Role of rs2231142 in the ABCG2-associated prognosis of OS. a, b Patients carrying the genotype AA were observed to have significantly increased overall survival rate and longer overall survival time than those carrying genotype CC $(p<0.05)$ c Genotype AA of rs 2231142 was indicative of remarkably lower expression of ABCG2 than genotype CC $(p<0.01)$ 
The genetic variants of ABCG2 were reported to be involved in cancer risk and chemotherapeutic response $[21,22]$. To illustrate the mechanism underlying the regulation of ABCG2 expression in OS tissues, a functional polymorphism rs2231142 of ABCG2 was genotyped in our cohort of patients. We confirmed that genotype CC of rs2231142 was indicative of remarkably higher expression of ABCG2. For OS patients receiving a therapeutic program that includes DOX, those with genotype CC could have poor outcome, which was in line with our finding that high expression of ABCG2 was associated with lower survival rate. Comparably, Morisaki et al. [23] found that cells transfected with the allele C of rs2231142 showed remarkably higher resistance to chemotherapy drugs than those transfected with wildtype, suggesting that rs2231142 may affect drug transport. Additionally, the rs2231142 has also been reported to be associated with increased adverse effects in response to chemotherapy treatment. Mizuarai et al. [24] found that rs2231142 mutant may decrease ATPase activity by 1.3 -fold as compared with the wild-type ABCG2. Taken together, these results suggested that rs2231142 may result in altered transport functions of ABCG2 transporter, which has important implications for the pharmacokinetics and drug-resistance profiles of chemotherapeutics. To conclude, we have provided the first data concerning the impact of ABCG2 polymorphism in the prognosis of patients with OS. Allele $C$ could be the clinical relevant allele which was indicative of decreased response to chemotherapy and poor prognosis. Early detection of this variant could be helpful in driving the choice of other alternative drugs to be used in chemotherapy.

Several limitations of this study should be addressed here. Due to the inherent drawback of retrospective study, the sample size of the OS patients was relatively small. In the future study, more OS patients need to be recruited for a stronger statistical power. Second, the mechanism underlying the influence of rs2231142 on expression level of ABCG2 remains undetermined, which is worthy of further investigation in the future study. Third, more in vitro experiments are warranted to determine the role of methotrexate and cisplatin in ABCG2associated chemotherapy resistance.

\section{Conclusions}

ABCG2 expression level was significantly associated with the response to chemotherapy and the overall survival of OS patients. Allele C of rs 2231142 was indicative of higher ABCG2 expression and associated with poor prognosis of OS. ABCG2 may become a promising therapeutic target for OS patients. Presence of allele C of rs2231142 could suggest the choice of other alternative drugs to be used in chemotherapy.

\section{Supplementary Information}

The online version contains supplementary material available at https://doi. org/10.1186/s13018-021-02204-z.

Additional file 1: Supplementary Figure 1. Representative cases with high tissue expression of ABCG2. 4 representative cases were selected to present the $\mathrm{HC}$ staining of ABCG2 in OS tissues. Case \# 08 and case \# 11 had strong signal intensity and positive staining cells, who were assigned to high expression group. By contrast, case \# 06 and case \# 09 had weak signal intensity and less positive staining cells, who were then assigned to normal expression group.

\section{Abbreviations}

OS: Osteosarcoma; ABC: ATP binding cassette; DOX: Doxorubicin; CCK8: Cell Counting Kit-8

\section{Acknowledgements}

We sincerely thank all the patients recruited in this study.

\section{Authors' contributions}

$\mathrm{HS}$ and YB collected the data and drafted the manuscript. $\mathrm{HY}, \mathrm{HB}, \mathrm{SQ}$, and $W L$ directed the radiographic measurements. SL reviewed and revised the manuscript. The authors read and approved the final manuscript.

\section{Funding}

This work was supported by the Natural Science Foundation of Jiangsu Province (Grant No. BK20191505)

\section{Availability of data and materials}

All data used in this study are available at the request of editors, reviewers, and the research community.

\section{Ethics approval and consent to participate}

Written consent was obtained from each subject. The histological study of surgical samples was approved by the Ethics Committee of the Affiliated Hospital of Nanjing University of Chinese Medicine. All experimental protocols and methods were carried out in accordance with relevant guidelines and regulations and complied with the Helsinki Declaration.

\section{Competing interests}

The authors declare that they have no competing interests. No benefits in any form have been or will be received from a commercial party related directly or indirectly to the subject of this manuscript.

\section{Author details}

${ }^{1}$ Department of Orthopedics, Sports Medicine Center, Affiliated Hospital of Nanjing University of Chinese Medicine, Hanzhong Road 115, Nanjing 210029, China. ${ }^{2}$ Department of Pathology, The Affiliated Drum Tower Hospital of Nanjing University Medical School, Nanjing, China.

Received: 6 November 2020 Accepted: 4 January 2021

Published online: 28 January 2021

\section{References}

1. Savage SA, Mirabello L. Using epidemiology and genomics to understand osteosarcoma etiology. Sarcoma. 2011;2011:548151.

2. Marko TA, Diessner BJ, Spector LG. Prevalence of Metastasis at Diagnosis of Osteosarcoma: An International Comparison. Pediatr Blood Cancer. 2016;63: 1006-11.

3. Rougraff BT, Simon MA, Kneisl JS, Greenberg DB, Mankin HJ. Limb salvage compared with amputation for osteosarcoma of the distal end of the femur. A long-term oncological, functional, and quality-of-life study. J Bone Joint Surg Am. 1994;76:649-56.

4. Jauregui JJ, Nadarajah V, Munn J, Pivec R, Kapadia BH, Lerman DM, Maheshwari AV. Limb salvage versus amputation in conventional appendicular osteosarcoma: a systematic review. Indian J Surg Oncol. 2018; 9:232-40.

5. Kim MS, Lee SY, Lee TR, Cho WH, Song WS, Koh JS, Lee JA, Yoo JY, Jeon DG. Prognostic nomogram for predicting the 5-year probability of developing 
metastasis after neo-adjuvant chemotherapy and definitive surgery for AJCC stage II extremity osteosarcoma. Ann Oncol. 2009;20:955-60.

6. Kim M, Kim DJ. GFRA1: a novel molecular target for the prevention of osteosarcoma chemoresistance. Int J Mol Sci. 2018:19:1078.

7. Wang H, Zhao F, Cai S, Pu Y. MiR-193a regulates chemoresistance of human osteosarcoma cells via repression of IRS2. J Bone Oncol. 2019;17:100241.

8. Lal S, Wong ZW, Sandanaraj E, Xiang X, Ang PC, Lee EJ, Chowbay B. Influence of $A B C B 1$ and $A B C G 2$ polymorphisms on doxorubicin disposition in Asian breast cancer patients. Cancer Sci. 2008;99:816-23.

9. Singhal SS, Singhal J, Nair MP, Lacko AG, Awasthi YC, Awasthi S. Doxorubicin transport by RALBP1 and ABCG2 in lung and breast cancer. Int J Oncol. 2007;30:717-25.

10. Wang J, Xue X, Fan K, Liu Q, Zhang S, Peng M, Zhou J, Cao Z. Moderate hypoxia modulates $A B C G 2$ to promote the proliferation of mouse spermatogonial stem cells by maintaining mild ROS levels. Theriogenology. 2020;145:149-57.

11. Wang WJ, Sui H, Qi C, Li Q, Zhang J, Wu SF, Mei MZ, Lu YY, Wan YT, Chang $H$, Guo PT. Ursolic acid inhibits proliferation and reverses drug resistance of ovarian cancer stem cells by downregulating ABCG2 through suppressing the expression of hypoxia-inducible factor-1alpha in vitro. Oncol Rep. 2016; 36:428-40.

12. Damiani D, Tiribelli M, Geromin A, Michelutti A, Cavallin M, Sperotto A, Fanin R. ABCG2 overexpression in patients with acute myeloid leukemia: impact on stem cell transplantation outcome. Am J Hematol. 2015;90:784-9.

13. Noguchi K, Katayama K, Mitsuhashi J, Sugimoto Y. Functions of the breast cancer resistance protein (BCRP/ABCG2) in chemotherapy. Adv Drug Deliv Rev. 2009;61:26-33.

14. Xu L, Xia C, Sun Q, Sheng F, Xiong J, Wang S. Variants of FasL and ABCC5 are predictive of outcome after chemotherapy-based treatment in osteosarcoma. J Bone Oncol. 2018;12:44-8.

15. Kim M, Jung JY, Choi S, Lee H, Morales LD, Koh JT, Kim SH, Choi YD, Choi C, Slaga TJ, Kim WJ, Kim DJ. GFRA1 promotes cisplatin-induced chemoresistance in osteosarcoma by inducing autophagy. Autophagy 2017;13:149-68.

16. Salas S, Jiguet-Jiglaire C, Campion L, Bartoli C, Frassineti F, Deville JL, Maues De Paula A, Forest F, Jezequel P, Gentet JC, Bouvier C. Correlation between ERK1 and STAT3 expression and chemoresistance in patients with conventional osteosarcoma. BMC Cancer. 2014;14:606.

17. Scholten DJ 2nd, Timmer CM, Peacock JD, Pelle DW, Williams BO, Steensma MR. Down regulation of Wnt signaling mitigates hypoxia-induced chemoresistance in human osteosarcoma cells. PloS one. 2014;9:e111431.

18. Tsai HC, Chang AC, Tsai CH, Huang YL, Gan L, Chen CK, Liu SC, Huang TY, Fong YC, Tang CH. CCN2 promotes drug resistance in osteosarcoma by enhancing ABCG2 expression. J Cell Physiol. 2019;234:9297-307.

19. Walters DK, Steinmann P, Langsam B, Schmutz S, Born W, Fuchs B. Identification of potential chemoresistance genes in osteosarcoma. Anticancer Res. 2008;28:673-9.

20. Kim CK, Oh S, Kim SJ, Leem SH, Heo J, Chung SH. Correlation of IGF1R expression with $\mathrm{ABCG} 2$ and $\mathrm{CD} 44$ expressions in human osteosarcoma. Genes Genom. 2018:40:381-8.

21. Nakagawa H, Wakabayashi-Nakao K, Tamura A, Toyoda Y, Koshiba S, Ishikawa T. Disruption of N-linked glycosylation enhances ubiquitinmediated proteasomal degradation of the human ATP-binding cassette transporter ABCG2. FEBS J. 2009;276:7237-52.

22. Sobek KM, Cummings JL, Bacich DJ, O'Keefe DS. Contrasting roles of the ABCG2 Q141K variant in prostate cancer. Exp Cell Res. 2017;354:40-7.

23. Morisaki K, Robey RW, Ozvegy-Laczka C, Honjo Y, Polgar O, Steadman K, Sarkadi B, Bates SE. Single nucleotide polymorphisms modify the transporter activity of ABCG2. Cancer Chemother Pharmacol. 2005;56:161-72.

24. Mizuarai S, Aozasa N, Kotani H. Single nucleotide polymorphisms result in impaired membrane localization and reduced atpase activity in multidrug transporter ABCG2. Int J Cancer. 2004;109:238-46.

\section{Publisher's Note}

Springer Nature remains neutral with regard to jurisdictional claims in published maps and institutional affiliations.

Ready to submit your research? Choose BMC and benefit from:
- fast, convenient online submission
- thorough peer review by experienced researchers in your field
- rapid publication on acceptance
- support for research data, including large and complex data types
- gold Open Access which fosters wider collaboration and increased citations
- maximum visibility for your research: over 100M website views per year
At BMC, research is always in progress.
Learn more biomedcentral.com/submissions

